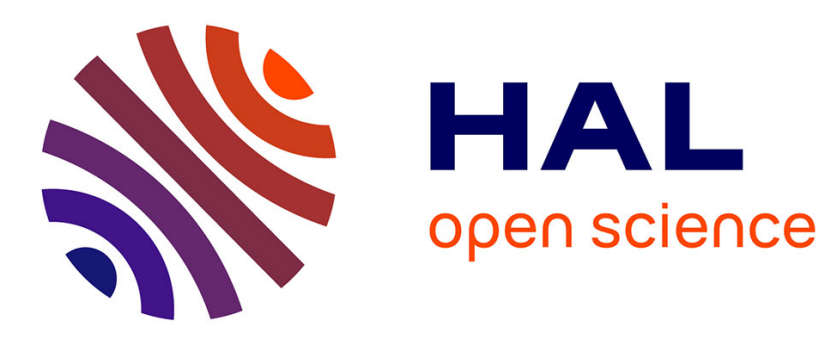

\title{
Multiple Criteria Decision Aiding: a Dialectical Perspective.
}

Wassila Ouerdane

\section{To cite this version:}

Wassila Ouerdane. Multiple Criteria Decision Aiding: a Dialectical Perspective.. 4OR: A Quarterly Journal of Operations Research, 2011, 9 (4), 10.1007/s10288-010-0147-3 . hal-01202232

\section{HAL Id: hal-01202232 \\ https://hal.science/hal-01202232}

Submitted on 24 Sep 2015

HAL is a multi-disciplinary open access archive for the deposit and dissemination of scientific research documents, whether they are published or not. The documents may come from teaching and research institutions in France or abroad, or from public or private research centers.
L'archive ouverte pluridisciplinaire $\mathbf{H A L}$, est destinée au dépôt et à la diffusion de documents scientifiques de niveau recherche, publiés ou non, émanant des établissements d'enseignement et de recherche français ou étrangers, des laboratoires publics ou privés. 


\title{
Multiple Criteria Decision Aiding: a dialectical perspective
}

\author{
Wassila Ouerdane \\ LAMSADE, University of Paris-Dauphine, Paris, France. \\ e-mail: wassila.ouerdane@lamsade.dauphine.fr \\ The date of receipt and acceptance will be inserted by the editor
}

\begin{abstract}
This is a summary of the Ouerdane's PhD thesis supervised by Alexis Tsoukiàs and Nicolas Maudet and defended on 01 December 2009 at the Université Paris-Dauphine, Paris. The thesis is written in English and is available from the author upon request. This work has the aim to investigate the different ways to use argumentation theory in a decision context. More precisely within multi-criteria evaluation models. The principal aim is to meet the needs in terms of explanations and revision during a decision process.
\end{abstract}

Keywords: Decision aiding process, Multiple criteria evaluation, Argumentation theory.

\section{Introduction}

Deciding is not an easy task: we are often facing problem situations where we are not sure what to decide (it is the case particularly when several points of view have to be considered in order to assess the quality of the different alternatives). Decision analysis is concerned with the process of providing decision support in such situations. We call such an activity "decision aiding". Decision aiding is the result of an interaction between an "analyst" (or expert) and a "client" (or decision maker), where the aim of the analyst is to support the decision maker to find a solution to his problem and to be convinced that this solution is a reasonable one. For that, the analyst and the decision maker are committed in an interactive process, where the main objective is eventually to reach a consensus upon the solution to a decision problem. Systems which aim at assisting people in decision making 
help the user to shape a problem situation, formulate a problem and possibly try to establish a viable solution to it. Decision theory and Multiple Criteria Decision Analysis (MCDA) have established the theoretical foundation upon which many decision support systems have blossomed. These approaches (and the formal tools coming along with them) focused for a long time on how a "solution" should be established. But it is clear that the process involves many other aspects that are handled more or less formally by the analyst. For instance, (i) the problem of accountability of decisions is almost as important as the decision itself. The decision maker should then be convinced by a proper explanation that the proposed solution is indeed the best (see Bouyssou et al. (2000)), and (ii) it should be possible, for the client, to refine, or even contradict, a given recommendation. Indeed, the decision-support process is often constructive, in the sense that the client refines its formulation of the problem when confronted to potential solutions.

Nowadays, decision-aiding situations are pervasive: they can occur in situations where the role of the analyst is taken by a non-expert, even in some extreme cases by an automatic tool. This means that several aspects usually delegated to the human analyst should (in these situations) ideally be handled by the decision-support system. The task is ambitious: in a "human-to-human" interaction - even though the dialogue is possibly supported by standard protocols (as in the case of constructing a value or an utility function or assessing importance parameters) which fix some explicit formal rules on how such a process can be conducted - the dialogue is handled through typical human interaction. A tool will be able to structure the dialogue on a formal basis in order to be able to control and assess what the device concludes as far as the user preference models are concerned and what type of recommendations (if any) is going to reach. In short, we need on the one hand some formal theory about preferences (and this is basically provided by decision analysis), on the other hand some formal language enabling to represent the dialogue, to explain it, to communicate its results, to convince the decision maker that what is happening is both theoretically sound and operationally reasonable.

Although there was until recently very little attention in the decision analysis literature to the use of decision theories and decision aiding methodology when the interaction occurs between a human and an automatic device (see Klein (1994) for a noticeable exception), the recent surge of automatic decision aiding tools on the Internet (recommender systems) have motivated a great deal of research, studying for instance the impact on the efficiency of recommendations when greater interaction with the user is allowed, or when explanations are provided $\mathrm{Pu}$ and Chen (2007). Due to the context however, only very simple interactions and models of preferences are envisaged (a typical consumer is not prepared to enter in a long preference 
elicitation process, or to discuss endlessly the benefits of a given options as opposed to another one). Our perspective in this work is different, as it is not to fully automatize the process. Instead, we rely on existing decisionaiding tools as developed in the MCDA community, and seek to enhance them with additional features as discussed above. Under such a perspective we consider that argumentation theory (Amgoud (2009)) provides a useful framework within which develop such a dialogue and a tool.

\section{How to use argumentation in a decision aiding process?}

Our aim through this work is to build a system that allows: (i) to present a recommendation that can be explicitly justified; (ii) to revise any piece of reasoning involved in this process, and be informed of the consequences of such moves; and (iii) to stimulate the user by representing naturally (sometimes visually) the exchanged arguments, possibly generating counterarguments. These different aspects trigger different problems and involve different models and mechanisms. As a consequence, our contributions in this work are of different nature, from the modeling exercise to the implementation of a prototype exhibiting the different features discussed in this thesis. More specifically, the following points have been investigated:

A hierarchical structure of arguments. We propose a first approach allowing to specify in argumentative terms the steps involved in an evaluation stage of a decision aiding process (see Ouerdane et al. (2008)). To do that, we make use of the popular notion of argument schemes. Argument schemes are forms of arguments that capture stereotypical patterns of humans reasoning, especially defeasible ones. Different approaches have investigated the use of argument schemes to decision-making (Ouerdane et al. (2010)). They greatly extend our understanding of the construction of argument schemes for action. Our claim in this work is that by presenting the reasoning steps of an evaluation process under the form of arguments schemes it makes justification possible and offers in turn the possibility to identify how these steps can be dialectically defeated. Thus, we propose a hierarchical structure where we identify three levels of argument schemes that are embedded. At the highest level the multi-criteria level, which is based on the aggregation level, which is in turn based on the Unicriteria level.

Choosing and justifying an aggregation procedure. The aim at the aggregation step is to construct a set of supporting reasons (or evidences) that allow to justify a given claim (or decision). What conclusion to provide depends entirely on the procedure that we should use to aggregate all the arguments that are both in favour and against that claim. Different procedures necessarily provide different results. In argumentation, such procedures are called proof standards Gordon et al. (2007). Usually, such proofs that are 
used are fixed a priori by the context. However (multicriteria) DecisionAiding (DA) is a context where it may be modified dynamically during the process, depending on the responses of the decision-maker. In fact, a delicate step in DA is to identify what kind of aggregation mechanism is appropriate in the decision context considered. Thus, the system needs to adapt and refine its choice of an appropriate method of aggregating arguments, so that it fits the preference model inferred from the interaction. In this work we address how this aspect can be handled in an argumentationbased decision-aiding framework. The first contribution is conceptual: the notion of a concept lattice based on simple properties and allowing to navigate among the different proof-standards is put forward. We then show how this can be integrated within the Carneades model Gordon et al. (2007), in order to discuss the acceptability of a procedure during the interaction.

Generating minimal explanations. At each step of the evaluation process, the decision maker can ask for explanations to clarify the reasoning steps assumed by the system, as well as the constructed recommendations and solutions. The idea is that the system generates automatically explanations by instantiating argument schemes constructed in the hierarchy. Moreover, the system seeks to provide the most "simple", "natural", explanation for a given recommendation. More precisely, the system provides the minimal evidence which allows to support a given conclusion. Thus, in this work we propose to examine different definitions of "minimality", depending on the language used to construct the explanation.

Other aspects were discussed in this thesis, such as handling revision and changes during the process, however, there are still many open questions and problems which deserve further attention. For instance, we believe that an experimental study aiming at analyzing the behavior of the decision maker in a real situation of decision support should allow to refine the types of reactions that the system should be prepared to deal with.

\section{References}

Amgoud L (2009) Argumentation for Decision Making, in: I. Rahwan, G. Simari (Eds.), Argumentation in AI Springer-verlag pages 301-320

Bouyssou D, Marchant Th, Pirlot P, Perny P, Tsoukias A, Vincke Ph (2000) Evaluation and decision models: a critical perspective, Kluwer Academic, Dordrecht

Gordon T, Prakken H, Walton D (2007) The Carneades Model of Argument and Burden of Proof, AI 171:875-896

Klein, D (1994) Decision analytic intelligent systems: automated explanation and knowledge acquisition, L. Erlbaum Associates Inc.

Ouerdane W, Maudet N, Tsoukias A (2008) Argument schemes and critical questions for decision aiding process, in: Ph. Besnard, S. Doutre, A. Hunter (Eds.), 2nd Inter. Conf. on Computational Models of Argument pages 285-296

Ouerdane W, Maudet N, Tsoukias A (2010) Argumentation Theory and Decision Aiding, in: J. Figuera, S. Greco, M. Ehrghott (Eds.), New Trends in MCDA (to appear)

$\mathrm{Pu}$ P, Chen L (2007) Trust Inspring explaining interfaces for recommender systems, Knowledge-Based systems 20:542-556 